Etnográfica

Revista do Centro em Rede de Investigação em

Antropologia

vol. $16(1) \mid 2012$

Vol. $16(1)$

\title{
Sentidos e significados de práticas juvenis em um bairro da cidade de Salvador, Bahia, Brasil
}

Meanings and significance of the cultural practices of young people in a neighbourhood of Salvador, in Bahia, Brazil

\section{Adriana Miranda Pimentel}

\section{(2) OpenEdition}

\section{Journals}

Edição electrónica

URL: https://journals.openedition.org/etnografica/1373

DOI: $10.4000 /$ etnografica.1373

ISSN: 2182-2891

\section{Editora}

Centro em Rede de Investigação em Antropologia

\section{Edição impressa}

Data de publição: 1 fevereiro 2012

Paginação: 31-51

ISSN: 0873-6561

\section{Refêrencia eletrónica}

Adriana Miranda Pimentel, «Sentidos e significados de práticas juvenis em um bairro da cidade de Salvador, Bahia, Brasil», Etnográfica [Online], vol. 16 (1) | 2012, posto online no dia 06 março 2012, consultado o 12 fevereiro 2022. URL: http://journals.openedition.org/etnografica/1373 ; DOI: https:// doi.org/10.4000/etnografica.1373

\section{(c) (i) (8)}

Etnográfica is licensed under a Creative Commons Attribution-NonCommercial 4.0 International License. 


\section{Sentidos e significados de práticas juvenis em um bairro da cidade de Salvador, Bahia, Brasil}

\section{Adriana Miranda Pimentel}

O artigo apresenta um estudo etnográfico que buscou conhecer os sentidos e significados das práticas culturais de jovens em um bairro pobre da cidade de Salvador, Bahia, Brasil. Partiu-se de um estudo do bairro, sua história de ocupação e urbanização, além de aspectos sociodemográficos e culturais dos moradores. Em seguida, foram realizadas entrevistas com os jovens, bem como registro em diário de campo de práticas artístico-culturais, religiosas e políticas desenvolvidas por eles. Essas práticas operam como "táticas de resistência": à invisibilidade do jovem no mundo adulto; às dificuldades de sobrevivência e às "tentações" e vicissitudes cotidianas. Essa leitura sobre o lugar e as práticas desenvolvidas pelos sujeitos que dele fazem parte permite compreendê-los para além das situações difíceis características dos bairros pobres das cidades.

PALAVRAS-CHAVE: jovens, bairro, práticas culturais, etnografia, cotidiano, resistência.

Meanings and significance of the cultural practices of young people in a neighbourhood of Salvador, in Bahia, Brazil - This article presents an ethnography study the aim of which was to understand the meanings and significance of the cultural practices of young people in a poor neighbourhood of Salvador, in Bahia, Brazil. The study began with an analysis of the neighbourhood, looking at its history of settlement and urbanization, in addition to the socio-demographic and cultural characteristics of the residents. Following this, the study dealt with the interviews conducted among young people and the artistic-cultural, religious, and political practices of these young people, which were recorded in a research diary. Such practices function as resistance tactics: resistance to the invisibility of the young person to the adult world, resistance to the difficulty of surviving and resistance to the 'temptations' and vicissitudes of daily life. This interpretation of the place and the practices developed by the individuals who are part of it allows for an understanding of these people which goes beyond the difficult circumstances typical of a poor city neighbourhood.

KEYWORDS: young people, neighbourhood, cultural practices, ethnography, everyday life, resistance.

PIMENTEL, Adriana Miranda (adriana.pimentel@ufba.br) - Instituto de Humanidades, Artes e Ciências Professor Milton Santos, Universidade Federal da Bahia, Brasil 


\section{ESTE ARTIGO É ORIUNDO DE UMA TESE DE DOUTORADO REALIZADA} entre os anos de 2005 e 2009, que buscou compreender os sentidos e significados de práticas culturais desenvolvidas por jovens em um bairro pobre da cidade de Salvador, Bahia, Brasil. ${ }^{1}$ A etnografia incluiu um estudo aprofundado do bairro, no intuito de conhecer o contexto de vida dos jovens e seus pontos de vista sobre o lugar, além de reconstruir trajetórias biográficas para compreender de que modo esses aspectos vinculam-se à criação/invenção de práticas localmente situadas. A temática surge de uma discussão, iniciada em outro estudo (Pimentel 2001), a respeito do modo como o campo da saúde interpreta e intervém sobre determinadas situações, tais como violências, abuso de bebidas alcoólicas e outras drogas, sexualidade e reprodução, concebendo-as como problemas de saúde específicos deste grupo e, em geral, sem levar em conta as condições de vida dessas pessoas em áreas fortemente precarizadas e os modos como elas constroem estratégias para lidar com as situações que se apresentam. Nesse sentido, busco outros significados e práticas que se originam das experiências de vida dos jovens dessas áreas, pois isto pode ser revelador da realidade e dos modos de existência nela possíveis.

A noção de práticas aqui empregada está intimamente relacionada aos espaços de vida onde elas se realizam. São "maneiras de fazer" cotidianas, como refere De Certeau, que vão sendo disseminadas ao longo do tempo, mas que não são reconhecidas ou validadas nos discursos correntes, em particular pelo saber científico. São formas de resistência que se fazem acontecer nas entrelinhas da história, por seres anônimos, através de "táticas silenciosas e sutis" (De Certeau 2003: 39), clandestinas, que permeiam o que está estabelecido. Essas táticas surgem das variadas combinações que compõem uma cultura própria, são as formas como os sujeitos fazem uso e consomem determinados bens culturais, não necessariamente dentro do padrão para os quais foram criados.

Os sujeitos constroem suas trajetórias por meio de práticas cotidianas, aproveitam ocasiões para o seu fazer, reorganizam "estruturas" previamente dadas e ressignificam modos de levar a vida, não propriamente compreendidos e aceitos pelos detentores de um tipo específico de saber. Há algo que ocorre em espaços nem sempre legitimados, nem sempre criados com uma finalidade determinada, mas que são reaproveitados e assumem novos contornos dados pelos sujeitos. Nesse sentido, novos saberes são produzidos e outras lógicas são permitidas e compartilhadas. Quando esses espaços são bairros pobres de grandes cidades brasileiras, estas práticas ou "maneiras de fazer" tomam novos sentidos.

1 A tese de doutorado foi defendida no Instituto de Saúde Coletiva da Universidade Federal da Bahia (UFBA) e orientada pelo prof. Ordep José Trindade Serra, a quem eu agradeço pelas contribuições. Agradeço também o financiamento da pesquisa pela Coordenação de Aperfeiçoamento de Pessoal de Nível Superior (Capes) e à revisora do texto, Iara Morata Martines. 
Há algum tempo a antropologia urbana se debruça sobre os usos que diferentes grupos fazem dos espaços da cidade (Magnani 2000, 2005; Magnani e Souza 2007; Velho 1999; Velho e Kuschnir 2003). Nessa perspectiva, a rua - símbolo da experiência urbana - é campo fértil para compreender práticas associadas a um modo de vida na cidade (Pais 1993; Pais e Blass 2004; Campos 2009). Espaços como este vão, pouco a pouco, definindo "lugares" (Augé 2004), construídos e re-capturados pelos sujeitos através do uso que fazem deles e dos sentidos que lhes atribuem, nos quais é possível a invenção/criação de "fazeres" à medida que bens (equipamentos, locais, recursos, relações) são apropriados e reapropriados. Na perspectiva da antropologia da juventude, Bucholtz (2002) analisa práticas culturais por meio de significados atribuídos pelos falantes - no caso, os jovens - nos próprios contextos onde estas práticas se realizam. Estas são signos de mudança e de construção de identidades, assim como juventude é também um signo, um shifter, que se cria e renova nas relações produzidas através dessas práticas. Para isto, é preciso que se dê outra leitura desses fazeres e dos atores que os desenvolvem, leitura esta acrescida do lugar onde uns e outros estejam situados - a rua, o bairro, a cidade.

Neste artigo, precisamente, discuto como estas práticas operam na interseção entre vicissitudes e possibilidades oriundas das experiências vividas pelos jovens no bairro de Cosme de Farias. Mais especificamente, analiso de que maneira estas práticas são efetuadas como "táticas de resistência" às situações que são incertas, instáveis, de insucessos, mas que podem também abrir e ampliar possibilidades. ${ }^{2}$

\section{UMA INCURSÃO ETNOGRÁFICA}

O estudo etnográfico foi desenvolvido com base em um survey do bairro de Cosme de Farias em que foram levantados dados sociodemográficos, fotografias, material jornalístico e bibliografia que remontam à história de ocupação e urbanização do bairro, e em um mapeamento das instituições, entidades e lugares não formalizados que se constituem em espaços de uso dos jovens. Este cenário foi construído com o propósito de conhecer o bairro em profundidade, do ponto de vista dos seus jovens moradores, e propriamente de identificar "lugares" onde os jovens convivem e de onde partem para a realização

2 É importante salientar que em minha pesquisa me detive nas práticas de jovens que têm resultado em espaços de criação, facilitando o trânsito e acesso dentro do bairro e na cidade, bem como ampliando as chances de vida. Com o trabalho de campo e uma maior proximidade com outros jovens do bairro, me dei conta de que há outras práticas que, provavelmente, também se configuram como "táticas de resistência", como o tráfico de drogas, por exemplo. Porém, fez-se uma escolha no sentido de conhecer modos de vida que têm, de algum modo, proporcionado mudanças e transformações na vida dos jovens, assim como no espaço onde vivem. 
de práticas específicas. Entre esses lugares, a praça central do bairro e a Rádio Comunitária foram nucleares neste processo.

A praça é um local privilegiado por ser praticamente o único espaço no bairro com área "livre", com algumas árvores, e por ser fim de linha dos ônibus - local de chegada e de partida. A praça tem seu lugar, não somente para os jovens; ela tem uma história no bairro. É o marco zero, onde se encontram residências mais antigas, os equipamentos de saúde e educação, a igreja de Santo Antônio, e onde se concentra o comércio local. Em todos os horários do dia ou da noite, há pessoas circulando, telefonando, consumindo algo, "batendo papo", ou simplesmente esperando o tempo passar. Ali também estão os jovens. Em alguns horários, a presença deles é mais numerosa em virtude das duas principais escolas e do intenso comércio e serviços ali localizados. Encontram-se também grupos, como os do "baba" (futebol), de skatistas, de capoeira ou violão. O lugar serve, ainda, para cortar cabelo, fazer as unhas, ouvir música, paquerar, fazer um lanche, vender drogas, além de outras atividades, que se modificam a depender do turno ou dia da semana.

Quanto à rádio, é espaço de trânsito, de convivência, de informação e de muita circulação de jovens. Ela surge por iniciativa de um locutor que, há aproximadamente oito anos, mantém o espaço e o abre para que jovens divulguem seus trabalhos e utilizem o equipamento para a realização de programas e atividades diversas. É um "lugar" e neste estudo assume particularmente esse papel, porque foi através dela que o mundo dos jovens que acompanhei se revelou para mim.

À medida que me aproximava deste cenário, dava-me conta desses "lugares" e de jovens que assumiam o bairro como deles e operavam práticas circunscritas a esta realidade. Passei, então, a acompanhá-los mais de perto, realizando entrevistas em profundidade, gravadas e posteriormente transcritas, observando atuações - ou "práticas", como preferi denominá-las - registradas em diário de campo, assim como materiais elaborados pelos jovens, como letras de músicas, jornais e escritos. Este material textual foi organizado e categorizado mediante o software NVivo versão 2.0; posteriormente, procedeu-se à análise de narrativa orientada pela perspectiva fenomenológica hermenêutica (Ricoeur 1994, 2000). A análise de narrativa nesta perspectiva coloca o foco nos sujeitos da ação, onde essa se desenvolve e em como ela é significada por esses sujeitos. Ricoeur (1994) prefere o uso da expressão "trama conceitual" aos termos ação ou prática. Para ele, a ação pode ser compreendida como algo determinado por uma motivação qualquer. Observa que existem circunstâncias em torno dessas ações que são negligenciadas, normalmente, e são exatamente elas que vão definir significados dos fazeres. Com isto, pensar em "trama conceitual", ou seja, no conjunto destes atores envolvidos ou, como o autor denomina, na "relação de intersignificação” entre todos os agentes e acontecimentos, é necessário para uma compreensão prática vinculada à compreensão narrativa do fenômeno 
(1994: 88-89). Assim, a narrativa é construída a partir das experiências dos sujeitos percebidas temporalmente. As experiências pessoais são narradas e, assim, a história vai sendo reconstruída à medida que os sujeitos da história vão refletindo sobre ela, à medida que contam e vão tecendo significados para ela.

Deste modo, foram entrevistados doze jovens, nove homens e três mulheres, afrodescendentes, de 18 a 30 anos, que viviam em Cosme de Farias e que desenvolviam práticas artístico-culturais, religiosas e políticas no bairro e voltadas para seus moradores. Os jovens entrevistados são lideranças de grupos específicos que desenvolvem determinadas práticas, denominados "comunidades de prática”, na expressão de Wenger (2001), da qual me apropriei para o estudo. Entre as práticas artístico-culturais, acompanhei seis bandas de rap $;^{3}$ entre as religiosas, dois grupos de doutrinas renovadas, um da Igreja católica e outro da Igreja evangélica neopentecostal; enfim, no que se refere à prática política, acompanhei as atividades de um conselho de moradores. ${ }^{4}$ Essas comunidades foram escolhidas por apresentarem algumas características comuns: a) são grupos com participação majoritária de jovens, que desenvolvem atividades no bairro conforme suas próprias necessidades ou desejos e mantêm autonomia em relação a instituições formais; b) o surgimento das práticas se deu em estreita relação com as trajetórias de vida dos jovens envolvidos; c) as atividades geram situações ou transformações no cotidiano, incorporam outros jovens e/ou moradores do bairro e favorecem o acesso a espaços no bairro e na cidade.

Com o tempo, fui percebendo, também, que essas comunidades existem, de algum modo, há algum tempo no bairro, ou seja, não são novas. Surgem de um desconforto causado por situações de vida e práticas institucionalizadas que não respondem às suas demandas mais urgentes, sejam essas práticas governamentais ou da sociedade civil; marcam um lugar diferenciado, quando apresentam críticas ao modo como as coisas funcionam; enfim, criam espaços novos e de transformação.

\section{O BAIRRO DE COSME DE FARIAS: UM CONTEXTO DE DIVERSIDADES}

Como muitos bairros de Salvador, Cosme de Farias era originariamente uma fazenda, com muitas árvores frutíferas. Isto já foi há muito tempo, em torno

3 O rap é um dos elementos que integram o hip hop, assim como o break, o graffiti e o scratching. O movimento hip hop chegou ao cenário brasileiro em fins da década de 1980, em particular nas áreas mais precarizadas de metrópoles como São Paulo e Rio de Janeiro. A marca do movimento, que mistura música, dança e poesia, é o descontentamento frente às questões que mobilizam os jovens nessas áreas degradadas, em especial às diversas formas de violência a que eles estão suscetíveis.

4 Acompanhei especificamente as comunidades do rap: as bandas Africaminas, Preto Sábio 05, Visão Urbana, Rapaziada do Morro (RM), Império Negro Nl e Ensino Básico; as comunidades da renovação, formadas pelos Justificados pela Fé e Ressuscitados; e uma comunidade política formada pelo Conselho de Moradores do Alto do Cruzeiro. 
de 50 anos atrás. Atualmente, Cosme de Farias é um bairro adensado, situado em área central da cidade e com população estimada em 40.000 habitantes - 50\% de crianças e jovens -, em 84 hectares de terra. Conforme o Censo 2000 (Bahia 2005), 14\% da população responsável pelo domicílio não possui rendimento ou o possui de forma irregular e a população economicamente ativa recebe entre meio e dois salários mínimos. O índice de alfabetização da população residente é relativamente elevado, porém o nível de escolaridade é baixo; cerca de um quarto desta população não tem instrução formal ou tem menos de um ano de estudo, e mais de metade dos chefes de família cursaram apenas os primeiros quatro anos do ensino fundamental.

O bairro é praticamente todo ocupado por casas de alvenaria, não possui um espaço livre ou área de lazer. Dispõe de poucos equipamentos governamentais que não respondem às necessidades básicas da população residente: um centro de saúde, uma casa do trabalhador ${ }^{5}$ e quatro escolas, de ensino fundamental e médio. Entretanto, existem cinquenta e sete entidades religiosas mapeadas: trinta e seis terreiros de candomblé (Santos s.d.), vinte igrejas evangélicas, entre históricas e neopentecostais, e uma igreja católica com um centro comunitário em outra localidade do bairro. Existem ainda vinte e uma entidades da sociedade civil, a maioria delas associações de moradores (Pimentel 2009).

Mais que dados sociodemográficos e institucionais, Cosme de Farias é visto pelos seus moradores como um "lugar tranquilo", "onde se conhece todo mundo", embora isto venha mudando nos últimos anos, principalmente em relação à violência movida pelo aumento no uso e tráfico de drogas. Esse contexto de escassez e precariedades abre espaço para as "bocas de fumo", entre outras atividades nem sempre desejáveis, e evidencia, do ponto de vista dos jovens, um lugar precário - comum entre bairros pobres das grandes cidades, onde a falta de recursos e oportunidades é a principal explicação para o fato. Por outro lado, esse mesmo bairro abre espaço também para outras práticas que surgem dessas mesmas vicissitudes experimentadas pelos jovens, como, por exemplo, as desenvolvidas pelas comunidades de práticas. Desse modo, Cosme de Farias deixa de ser um bairro pobre e com características semelhantes às de outros bairros da cidade de Salvador e passa a ser o bairro de Cosme de Farias, um espaço singular e de diversidade.

\section{PRÁTICAS COMO “TÁTICAS DE RESISTÊNCIA”}

A resistência comumente é compreendida como algo relacionado à oposição. No dicionário, é possível encontrar definições que vão nesse sentido: força que

5 Equipamento vinculado à Secretaria da Economia, Emprego e Renda do Governo do Estado, que se destina a qualificação profissional, cursos de inclusão digital, entre outras atividades oferecidas para jovens da região administrativa. 
se opõe a outra, luta em defesa, oposição ou reação à força opressora, obstáculo, empecilho, recusa (Ferreira 1988), entre outras tantas. Para além destas definições, o conceito de resistência é bastante polêmico e controverso. Um dos aspectos que chama atenção é sua relação com os mecanismos de poder, objeto de estudo e de grande interesse das ciências humanas, particularmente nos estudos feministas.

Até a década de 1970, estes estudos centravam-se sobre o papel de vítima que mulheres assumiam em determinados contextos de subordinação ao poder masculino (Conceição 2009). Posteriormente, as discussões levaram à produção de uma dicotomização de posições, entre objeto-vítima e sujeito-resistente (Convery 2007). Essa polarização gerou, por um lado, uma forte e indiscriminada desvalorização, às vezes rejeição, do que é considerado vitimismo e passividade e, por outro, uma sobrevalorização das ações, principalmente no tocante à intenção que as determina - o que Abu-Lughod (1990) chamou de "romantização da resistência".

Perspectivas atuais têm apontando para posicionamentos sutis das mulheres em espaços microssociais, através de práticas localizadas que podem indicar formas de enfrentamento no intuito de transformar o status de vítima em contextos específicos onde ocorrem (Bucholtz, Liang e Sutton 1999). A análise das ações nos contextos próprios em que se realizam também permite refletir sobre aspectos que concernem a relação entre poder e práticas de forma geral.

Com base no conceito de resistência desenvolvido por Foucault (s.d. [1984]), segundo o qual "onde não há poder, não há relações de resistência”, Abu-Lughod (1990), por exemplo, sugere que a resistência pode ser usada para diagnosticar a presença de poder. Cabe ressaltar, todavia, que práticas relacionadas a mecanismos de poder não são vistas de forma homogênea. Assim, a resistência não é uma condição de negação de alguma coisa, de oposição apenas, mas sim um processo de criação que busca transformar uma situação ativamente. Convery (2007) refere que há controvérsias se estas práticas mais seriam estratégias de sobrevivência, o que comumente se conhece como resiliência, ou se, de fato, elas são transformadoras de ideologias e modificam situações aparentemente estabelecidas. Para Weitz (2001), estas práticas não somente recusam a subordinação, mas o fazem desafiando as ideologias que lhe dão sustentação. Weitz salienta, ainda, a importância de situar, localizar, o contexto onde ocorrem as práticas, pois deste modo será possível analisar o impacto das manifestações de poder.

Ao refletir sobre práticas juvenis em bairros pobres da cidade, reconheço a importância do contexto onde essas práticas cotidianas ocorrem para compreender outras dimensões da resistência e compartilho isto com alguns autores contemporâneos. Para Adorno, por exemplo, os estudos das cidades e da vida urbana têm permitido compreender grupos que passam a buscar formas de resistência àquilo que o espaço urbano proporciona, "construindo um território 
para a individualidade" (1999: 23). A cidade é um lugar de resistência, para Magnani, quando grupos se apropriam dos espaços, criam novas formas de sociabilidade em "não lugares", modificam a "arquitetura do lugar, tentativa de ressemantizar a cidade através da produção de espaços carregados de sentido, em busca da reanimação do genius loci, o espírito do lugar" (Magnani 2006: s.p.). Cabe, portanto, compreender a cidade pelo olhar de quem nela vive: o modo como os sujeitos vão ocupando, transitando e construindo formas possíveis de viver a partir das condições e estilos, mas, principalmente, das suas relações, das suas formas de organização e da sua atuação nestes espaços. Essa perspectiva busca abarcar a positividade dos espaços onde estão os sujeitos, no sentido da reapropriação que eles fazem desses espaços, e favorece o pensar as vicissitudes dos jovens do ponto de vista dos sujeitos que vivem nestes espaços - da leitura que fazem dos espaços, das dificuldades enfrentadas e do uso dos recursos e possibilidades.

Richard Sennett (2003), com base em uma perspectiva histórica da cidade, retrata a dinâmica dos corpos humanos no espaço urbano e assinala o modo como esses corpos se colocam, como se aproximam, se distanciam, interagem e como revelam a complexidade da vida nas cidades. Esses corpos "sustentam a resistência à dominação" (Sennett 2003: 24), uma resistência que é marcada pelo modo como os corpos se deslocam, se movem, como traduzem e manifestam as formas de dominação, em um tempo e um espaço determinados.

Na perspectiva fenomenológica hermenêutica, resistência implica uma oposição, mas a algo que lhe é também constitutivo; é indissociável daquilo a que se opõe (Ayres 2001). Assim, a resistência a alguma coisa permite considerar a existência de algo que faz parte do mundo e que pode, também, gerar desconforto; é o modo como os jovens vivem as experiências e padecem com elas, embora busquem mecanismos de enfrentamento através das possibilidades que estão dadas inclusive por esses desconfortos. Nessa perspectiva, a existência de algo se dá pela própria experiência de relação com o outro, como a percepção da existência de alguma coisa que faz parte do mundo dos jovens e, portanto, deve ser contemplada para a abertura de novas possibilidades.

Neste estudo observei que as práticas não se opõem a uma situação propriamente estabelecida, mas sim convivem com essas situações e "mobilam" o mundo na medida em que elas existem-resistem no mundo dos jovens. Para De Certeau (2003), as práticas são compreendidas como "táticas de resistência" quando se situam como contrárias ao que está previamente estabelecido, colocando-se, portanto, como possibilidades para grupos menos favorecidos ou em condição de opressão quando inventam novos modos de fazer. Assim, são possibilidades encontradas nos contextos de vida dos jovens, não como forma de embate às adversidades, mas como "brechas" que viabilizam formas de existência possíveis, sonhos possíveis. 
Os discursos dos jovens e as observações de campo me fizeram perceber que algumas experiências vividas, nem sempre bem sucedidas, são por eles transformadas. Três aspectos mostraram-se relevantes para que os jovens se posicionassem de outro modo e produzissem práticas que se configuraram como "táticas de resistência": a) a invisibilidade no mundo adulto; b) as dificuldades de sobrevivência; c) a iminência das "tentações" e vicissitudes do cotidiano.

\section{A INVISIBILIDADE NO MUNDO ADULTO:}

\section{UMA QUESTÃO DE IDADE OU DE DISTRIBUIÇÃO DE PODER?}

Ser reconhecido socialmente implica ser aceito por um outro, neste caso por um grupo de pessoas, e, portanto, vincula-se à noção de identidade proposta por Ricoeur (1996). ${ }^{6}$ A identidade se constitui a partir desses outros. Quando os jovens falam de uma ausência de reconhecimento de suas possibilidades para fazer coisas, referem-se a um grupo de pessoas que tem legitimidade para realizá-las, ou seja, está "capacitado", é "responsável” ou possui mais habilidades, grupo este representado pelos adultos. Do ponto de vista dos jovens, há um conflito entre esses mundos.

A questão da invisibilidade pelo fato de serem jovens aparece de modo bem evidente na comunidade política. Os jovens fundam o Conselho de Moradores do Alto do Cruzeiro na perspectiva de transformar relações sociais subjugadoras e assistencialistas - comuns no bairro - em relações mais autônomas e participativas entre moradores, lideranças e autoridades vinculadas ao local. Questionam as entidades que buscam suprir necessidades imediatas dos moradores, distribuindo colchões e cestas básicas e realizando festas em datas comemorativas com oferta de brindes (cadernos e lápis na volta à escola, brinquedos em festas comemorativas das crianças e/ou natalinas, entre outras), com vistas a privilégios e ganhos futuros. Ao contrário, eles defendem uma prática política que problematize as questões mais prementes do bairro, contribua para a organização dos moradores e promova a participação. Isto aparece no discurso de um dos jovens fundadores da comunidade:

"Enquanto eles 'tavam no assistencialismo, que o modelo deles era aquele modelo que dá cobertor p'ra o frio, o colchão e aí pronto... A gente começou a conscientizar, botar o jornalzinho, a participar das conferências, a brigar de forma diferente, 'tar dentro, a participar das conferências de saúde. Eu fui

6 Ricoeur define os termos mesmidade e ipseidade como aspectos constituintes da identidade. Para Mendes, estes termos caracterizam "a estabilidade que deriva dos hábitos, disposições e identidades adquiridas como alteridades assumidas enquanto membros de certos grupos e comunidades - noção de caráter. [...] A identidade-ipseidade integra a alteridade, de tal forma que o indivíduo não se consegue pensar sem o outro, tendo que dialogar continuamente com a polissemia da alteridade" (2002: 521). 
o primeiro..., o primeiro delegado de uma conferência de saúde de [...], do Alto do Cruzeiro. Aí, comecei a marcar posição; aí foi que as pessoas foram me respeitando..." [Castor]

Essa participação, que se mostra na representação do bairro em eventos, conferências e instâncias de decisão, importantes do ponto de vista político, gerou desconforto no bairro, especialmente de gestores e lideranças mais antigas. Segundo Castor, eles se sentiram pressionados e colocados em evidência pelo fato de não estarem correspondendo ao que se espera de um líder comunitário.

Os jovens ressaltam as dificuldades no processo de articulação com coordenadores do Distrito Sanitário, dirigentes da Prefeitura e até mesmo com lideranças. Segundo eles, isso deve-se ao fato de serem jovens e não estarem "autorizados" para tais demandas. Também evidenciam seus feitos e o quanto essa "autorização" vem mudando à medida que eles têm tomado posições de destaque e acessado canais de comunicação que, até então, não existiam para eles e nem mesmo para o bairro. Fazem questão de mostrar eventos e mudanças que têm ocorrido a partir do momento em que assumiram posições em fóruns e espaços políticos na e da cidade, modificando a ideia preconcebida de que os jovens não teriam responsabilidade para assumir. Nesse sentido, a relação entre juventude e irresponsabilidade, que aparece com mais ênfase no discurso desses jovens para explicar a postura dos "adultos" (lideranças e dirigentes de órgãos), evidencia o preconceito face à caricatura da juventude veiculada socialmente, mas, também, apresenta as dificuldades e conflitos inerentes à distribuição de espaço político e às posições de poder no bairro.

“Deveria ser o Distrito ou o Posto [de Saúde] só que, devido à gente ter ido buscar... A gente tinha muita dificuldade mesmo p'ra poder realizar algumas coisas, aí o que a gente fez? A gente partiu p'ra fora. A gente começou: Conferência, Secretaria de Saúde, audiência com o secretário, esse negócio todo, a gente quebrou... Hoje, eu posso te dizer uma coisa: infelizmente, hoje, dentro da saúde, a gente tem mais facilidade de buscar algumas coisas p'ra Brotas [Distrito de Saúde] do que o próprio Distrito; hoje, o Distrito faz questão de ser parceiro nosso. Porque antes era difícil; hoje, eles fazem questão de 'tar nos eventos, convida a gente; hoje, a gente propõe $70 \%$ dos eventos no Distrito; a gente é que fez a proposta e correu atrás" [Pólux].

O reconhecimento das instituições e lideranças no bairro se deu, conforme os meus interlocutores, no momento em que desistiram de conflitar internamente e resolveram transitar e articular-se com outras instâncias de poder na cidade. Passaram do lugar do incômodo para um lugar de parceiros; começaram a ser ouvidos e procurados para a realização de ações no bairro. Em uma conversa, 
referiram as dificuldades para desenvolver uma prática política diferente: é preciso conviver com o assistencialismo, com o tráfico de drogas, com a corrupção, com a violência, pois isso é parte constitutiva do lugar. Na experiência política e comunitária, vão percebendo que não há como enfrentar essas situações como se fossem inimigos, porque estão arraigadas, fazem parte do modo de vida das pessoas. É também na experiência cotidiana que vão se dando conta de que é estando ali, com as pessoas e suas expectativas, e lidando com as situações que se apresentam, que será possível identificar novas possibilidades:

"Você tem que transformar esse assistencialismo com uma ação emergencial, entendeu? E não perder o foco de que o que vai resolver é a ação... [...] Vamos supor, não há uma discussão p'ra áreas de prioridade. Muitas das vezes a ação é só p'ra dizer que teve presente no bairro, entendeu? Eu disse: 'não, tudo bem, você vai chegar lá na segunda-feira e oferecer o sopão; e terça, quarta e quinta, o que eles comem?' Embora a gente apoie, [por]que, se você andar no bairro, você vê várias pessoas catando lixo; tem gente que vive do lixo, aqui, hoje em dia. Mas, é como eu 'tou te falando, eu vejo o assistencialismo como uma coisa emergencial, uma campanha... Agora, tem gente que vê o emergencial como uma forma de se promover. Agora, na prática é difícil porque você tem as entidades que são viciadas, você tem as pessoas que são viciadas" [Castor].

Nesse fragmento, Castor identifica algumas situações existentes no bairro e não nega a necessidade de soluções rápidas, mesmo que paliativas, como a distribuição de sopa; entretanto, percebe que a prática não pode terminar no emergencial. Um dos aspectos que parece sinalizar para isto foi observado em um evento na praça, quando um dos integrantes desta comunidade, vinculado à Igreja católica e adepto da prática de entrega da sopa, também passou a discutir esses aspectos com outras entidades. Desse modo, os jovens tentam fazer valer seus princípios e posições políticas - um outro modo de fazer política local - e, ao mesmo tempo, tentam garantir um lugar nesse espaço de disputa e de reconhecimento, particularmente de "provação", por serem jovens.

\section{AS DIFICULDADES DE SOBREVIVÊNCIA:}

DE GANHOS MATERIAIS A GANHOS SIMBÓLICOS

A situação de pobreza e precariedade em que todos estão envolvidos mobiliza ações dos jovens. Não apenas ações visando resolver carências materiais como, de algum modo, as associações e lideranças já fazem. Esses jovens têm colocado em pauta uma reflexão sobre a sobrevivência que transcenda a dimensão dos ganhos materiais e que considere os ganhos simbólicos. Que busque compreender outras dimensões da sobrevivência, que implique dignidade e sentido 
em relação ao que eles desejam e se propõem a fazer. Para eles, a sobrevivência não é simplesmente "dar um jeito" de passar os dias, suprir a fome mais imediata e aceitar os pequenos ganhos como dádivas; ao contrário, significa lidar com a existência destas situações encarando-as de frente e fazendo delas algo que tenha sentido para eles.

O que percebo nos jovens é que eles estão envolvidos neste mundo, percebem o que está ali ao alcance das mãos e fazem uso dessas situações para transformá-las. Nem sempre o uso que fazem das coisas é o mesmo para o qual a coisa foi criada, pois buscam outros canais de acesso. Este outro uso que fazem das coisas é uma garantia de sobrevivência em um bairro com estas características, tal como Costa (2010) também sinalizou no seu estudo sobre representações da juventude na Baixada Fluminense; é, também, uma chance de mudar de posição neste cenário e uma possibilidade de sonhar. Este aspecto está intimamente relacionado aos fazeres das comunidades do rap.

Charles é um jovem rapper do bairro. Ele não conheceu o pai, mas conviveu com o padrasto, que era músico e que lhe apresentava todas as manhãs estilos e músicos diferentes, como Elza Soares e Chico Buarque. Trabalhou alguns anos na feira livre com a mãe, mas em geral a maior parte das atividades que realizava era o que ele chamava de "biscates". Atualmente, toca com uma banda de rap que tem avançado bastante, particularmente devido à participação do grupo em uma organização não governamental que atua com jovens na cidade:

"Eu quero ganhar pelo que eu trabalho, eu quero fazer bem e ganhar bem, sacou? Porque está difícil, tenho meu filho que tem despesa, moro só e pago aluguel, sou separado e pago pensão, então é muita dificuldade para você tá e depois que você passa isso tudo é muito difícil, mas quando você 'tá em cima do palco é massa, ali dando autógrafo e depois você volta p'ra sua casa, depois você volta p'ra pegar o buzu de novo, 'tá ligado?" [Charles]. ${ }^{7}$

Parecem dois opostos e, por vezes, são. Os jovens fazem manobras para dar conta da sobrevivência e, na mesma medida, pegar o que sobra e investir no trabalho que lhes amplia as chances de vida. Conversando com Charles em sua casa de um cômodo, no alto de uma das longas escadarias comuns do bairro, ouvia seu relato e conseguia imaginar o sentido que dava à cena "estar no palco dando autógrafos" e "depois pegar o buzu". Nesse momento, eu não podia deixar de reparar ao redor: estávamos sentados na cama de solteiro onde dorme, em um quarto de aproximadamente cinco metros quadrados, com roupas, objetos pessoais e, entre tantas coisas espalhadas pelo chão, uma panela 
com arroz. À nossa frente, a porta e uma janela de onde espiávamos seu filho de dois anos que estava chegando com um dos integrantes da comunidade (a nosso pedido, para que Charles pudesse me conceder a entrevista). Em conversa com outros integrantes da banda, eles contam uma recente viagem para São Paulo, para tocar com Arnaldo Antunes, "um sonho" segundo eles, para depois retornar à cidade, às mesmas condições de vida de antes. ${ }^{8}$ Esse cenário que acabo de apresentar ilustra certa contradição aparente, em que o jovem sobrevive em situações precárias de vida e dificuldades para se manter, mas, ao mesmo tempo, experimenta situações que lhe oferecem a possibilidade de sonhar e vivenciar outras realidades.

Parte das composições de Charles é fruto dessas contradições e vicissitudes. Uma música da banda narra o dia a dia dos trabalhadores braçais e o cotidiano da maioria dos jovens de Cosme de Farias, bem como o cotidiano de alguns membros da banda. Desabafo do Trabalhador é uma música do grupo que está no YouTube na forma de clip. ${ }^{9} \mathrm{Diz}$ assim:

"Vou dormir, vou descansar/ Cedo eu vou acordar, desde cinco da manhã, já deu, tenho que trabalhar/ Trabalho o dia inteiro/O trampo é de pedreiro/ Cansaço, dor no corpo, no outro dia já estou disposto/ Muitas dores no corpo/ Parece que a escravidão nunca vai cessar um pouco/ Trabalho de peão, vira concreto, racha o chão/ Muita dificuldade e calo na mão/ Trabalho redobrado e o dinheiro ele é regrado/ Não sei mais o que faço nesse mundo de explorado [...] / Há, tá, tá, tá, trabalhador desabafa" [Desabafo do Trabalhador, Império Negro NI].

A letra da música descreve as más condições do trabalho braçal, duro e desgastante, que a maioria dos homens das periferias urbanas realiza. O clip, assim como a letra da música, revela uma faceta característica do bairro, a dos trabalhadores da construção civil. O bairro cresce todo o tempo, atualmente para cima, porque não há mais espaço lateralmente. Os jovens aprendem desde cedo o trabalho de pedreiro, que para alguns nunca termina. Entretanto, os jovens das comunidades acompanhadas atribuem outros sentidos e significados às experiências de trabalho e aos ganhos materiais, quando os utilizam para alimentar os sonhos. Muitos continuam a realizar esses trabalhos que lhes permitem comprar ou alugar o equipamento, gravar em estúdio, comprar instrumentos e discos, ir a shows e, assim, conseguem administrar o ganho também com atividades que lhes deem mais sentido. Isso aconteceu, por exemplo, com Mago, que fez da atividade de pedreiro uma forma de ganhar dinheiro

8 Arnaldo Antunes é um importante cantor e compositor do cenário musical brasileiro.

9 YouTube é um website que permite compartilhar vídeos em formato digital e, atualmente, é muito utilizado pelos jovens para divulgar seus trabalhos artísticos, por exemplo clips de músicas. 
para assumir, de fato, a banda de rap de maneira ativa. Ao longo do trabalho de campo eu o acompanhei nos finais de semana, quando ele levantava a sua casa e construía cômodos que lhe serviam tanto para melhorar sua condição de moradia, quanto para ganhar algum dinheiro alugando-os posteriormente. Durante a semana, faz "de um tudo": revende um tipo de sorvete ensacado e tantos outros biscates que encontra. Desse modo, consegue sobreviver e investir no sonho de ver a banda continuar. Ele destina parte de seu tempo a escrever as músicas, encontrar estúdios para gravar, preparar o material, contatar músicos e disc jockeys, articular espaços no bairro para os ensaios, divulgar o trabalho e, além disso, alimenta a perspectiva de criação de um projeto para jovens de Cosme de Farias, via movimento hip hop. Participei de um programa de rap que Mago realizava todas as sextas-feiras à tarde na Rádio Comunitária, programa intitulado Luminosidades Repercussivas. Nele, Mago informa sobre eventos de rap, divulga os trabalhos de bandas locais e de outros lugares, discute temas de interesse dos jovens, tais como drogas, violência, cidadania, rádio comunitária, entre tantos outros. $\mathrm{O}$ acesso à rádio através do trabalho da banda é um exemplo de como essas práticas permitem o trânsito para determinados espaços no bairro e transformam situações adversas em novas perspectivas.

Há diferenças entre as comunidades de rap acompanhadas dentro do mesmo espaço geográfico, assim como também foi identificado por Fradique (1999) no seu estudo sobre os grupos de rap lisboetas. As que se situam em áreas mais centrais do bairro, com uma rede de apoio (família e amigos) mais ampliada, têm maiores chances de ganhos e de abertura de espaços. Nessas áreas vivem as pessoas que já estão no bairro há mais tempo, possuem uma renda mais alta e estão mais próximas dos poucos equipamentos públicos e comércio local disponíveis. De certo modo, as comunidades que se concentram nas áreas centrais, onde as moradias e infraestruturas estão em melhor estado, possuem uma condição melhor para arranjos e articulações, enquanto outras, localizadas em áreas mais periféricas do bairro, entre encostas e baixadas, devem galgar esse espaço, inclusive na relação com bandas e jovens que já conquistaram esse lugar. Isso favorece, por exemplo, maior investimento nas bandas, na medida em que adquirem instrumentos musicais, estúdio de gravação, acesso a mídias e contatos externos. Esse investimento contribui para a expansão das práticas, com abertura de espaços, dentro e fora do bairro, e um maior trânsito por estes espaços. Esses aspectos são ressaltados por Magnani, quando afirma que o espaço no qual os jovens interagem não deve servir como mero cenário e sim como um "produto da prática social acumulada desses agentes" (2005: 177). Tal prática é constituída pelas experiências de significado, que se dão sempre com outros.

Do mesmo modo que algumas práticas atuam como formas de resistência à invisibilidade "necessária" ao jovem e às dificuldades de sobrevivência, 
também operam como formas de "salvação" e proteção frente às "tentações" e vicissitudes cotidianas.

\section{A IMINENCIA DAS “TENTAÇÕES” E VICISSITUDES DO COTIDIANO}

A ideia de "salvação" relacionada às práticas que os jovens realizam está presente em todas as comunidades acompanhadas no estudo. Em um encontro da comunidade Ressuscitados, um jovem fala da sua grande contribuição para que ele deixasse de beber, retomasse o curso de sua vida com a família e retornasse ao trabalho. Depois de contar sua história de infortúnios diante da comunidade, apoiado inclusive pelos outros integrantes, ele refere: "É como uma estrada com espinhos no início, mas que Jesus vai abrindo e deixando o caminho livre para que Ele possa passar no final" [Prometeu].

As comunidades da renovação se apresentam para os jovens como lugares de um fazer e de poder ser "alguém" na vida. As práticas que eles realizam, tais como as de evangelização, formação/educação para os jovens, obras sociais e grupos de convivência são situações potenciais de troca e solidariedade. Essas práticas protegem das "tentações" e vicissitudes, segundo os jovens interlocutores. As "tentações" por eles descritas são: uso de drogas e de bebidas alcoólicas, agressões, sexo fora do casamento, práticas homossexuais, delitos, desespero por falta de expectativas e de projetos futuros. Algumas vezes, essas "tentações" também estão na ordem do não dito e aparecem como uma luta diária, são "tentações que só com a força de Deus podem ser controladas". São tentações que os rodeiam e das quais eles precisam ou tentam, a cada dia, livrar-se. A prática religiosa é uma forma de salvação:

"A religião, ela é um protetor, ela protege. Protege no que se diz das coisas, das drogas, do sexo... [...]. Eu tenho talvez, esse obstáculo em minha vida; eu percebo que Deus, ele me chama p'ra algo... p'ra águas mais profundas... [...] Tem um segredo da vida, tem até um escritor que diz: 'Você cai sete, levante oito'. Eu não posso me acomodar; os fracos que se acomodam; há os pecadores que pecam" [Prometeu].

A prática religiosa, ou seja, as atividades que devem cumprir cotidianamente através da comunidade religiosa, bem como a "consciência" dos pecados e da necessidade do perdão, fazem com que os jovens estejam atentos e protegidos das tentações. "Ele [Deus] esquece dos nossos pecados quando nós nos arrependemos..." [Prometeu]. Outra jovem refere ter tido síndrome do pânico há alguns anos e caracteriza o problema: "Não conseguindo sair de casa, estar mal em multidões, não ter vontade de fazer nada, não ter projetos ou sonhos". Depois que entrou para a Igreja, conheceu pessoas, integrou uma banda musical, conheceu o namorado e passou a se sentir outra pessoa. Seu projeto de 
vida é casar-se com o namorado, ir para São Paulo, onde ele mora atualmente, e fazer um curso de jornalismo.

Lua, jovem que recentemente deixou a religião, trabalha atualmente como locutora de carro de mensagens, representante de produtos em supermercados, além de outros tipos de atividades que realiza para se manter. Sonha ser locutora de uma rádio de maior difusão e cantora. Parte dessas práticas teve origem na Igreja que frequentava. Ela reconhece a importância da religião, como uma passagem necessária em um determinado momento de sua vida:

“[...] por eu ter seguido a religião foi que eu não entrei nesse mundo de violência que é p'ra todos que estão aqui hoje, entendeu? Não cheguei a me viciar, porque assim, toda a situação que eu já tinha vivido, toda a minha história que eu já tinha vivido, como eu lhe falei, as pessoas que normalmente passam por essa situação, né, com os pais, com a família, sofre [m] rejeição do pai, agressão, essas coisas todas influ[em] normalmente numa coisa ruim, ela não vai nunca ter nenhum pensamento bom na vida" [Lua].

Lua não mais pertence à comunidade religiosa, mas ressalta a importância dessa experiência como algo que lhe deu proteção e suporte no enfrentamento das adversidades. Nesse sentido, a prática teve seu lugar. Entretanto, há algo que me chama atenção: ao mesmo tempo em que as práticas das comunidades religiosas ofereceram suporte, elas também reafirmaram e mantiveram avivados os "motivos" que levaram os jovens à conversão. Do mesmo modo, conheci jovens nas comunidades de renovação que falavam do grupo com orgulho e manifestavam satisfação pelo pertencimento, mas não deixavam de relatar as experiências de padecimento que os levaram até ela. Muitas histórias de uso continuado de álcool e drogas e de "vida fácil", como referiram, desencadearam perda de laços familiares e desemprego. Nesse sentido, o processo de conversão resultou numa grande mudança de vida. É interessante observar como as adversidades e "tentações" fazem parte desse quadro e devem ali permanecer. É uma convivência necessária para que o jovem se mantenha firme na sua escolha e contribua na ajuda aos outros da comunidade. Estas situações de desconforto passam a ser ressignificadas pelos jovens através das práticas que realizam nas comunidades e, neste processo, eles se sentem possibilitados para retomar a vida e constituírem projetos futuros. Por um momento, estas práticas podem sinalizar certa conformidade dos jovens com as contingências de vida a que estão sujeitos no bairro, por exemplo, em relação ao lugar que a religião ocupa, especialmente o pentecostalismo, no cenário contemporâneo de bairros pobres das cidades brasileiras (Novaes 2005). Porém, é importante destacar que são sempre escolhas circunscritas a um "campo de possibilidades", tal como o descreve Velho (1994, 2006). 
Entre algumas comunidades do rap, o estilo rapper, que se expressa no cabelo trançado ou bem cortado, roupas folgadas e de griffe, bonés e tênis de marcas famosas, favorece a proteção na rua, seja frente aos "bandidos", seja em relação à polícia. Isto não vale para todas as comunidades do rap, pois há discordâncias. Para algumas delas, esses acessórios estimulam as batidas policiais, exatamente porque são signos do rap e isto motiva os conflitos com a polícia. Todavia, para Mago e Cristiano, ser do rap favorece o respeito e a confiança. Percebo que há outros elementos envolvidos nesse favorecimento, como, por exemplo, o tipo de roupa que trajam. Vestir-se bem implica status, mas também funciona como um modo de ser reconhecido, "respeitado", eu diria, como proteção contra a violência policial:

"Até a polícia, mesmo, se comporta de outra forma, né, quando vê uma pessoa que cria cabelo, porque bandido não usa cabelo grande por causa da identidade, porque senão ia ser muito fácil pegar esse bandido assim. Já passei por certos lugares, já fui enquadrado! Tanto de, assim, maltratado, né, como também, com cabelo, me trataram muito bem, me pediram desculpa. Não sei também se é porque eu 'tava bem arrumado, parecendo um artista mesmo, 'tava voltando de um som..." [Mago].

O cabelo trançado, o estilo rapper, vincula-o ao "movimento". A roupa também é um instrumento importante. São signos diferenciais que ampliam o trânsito e uso que fazem do bairro e da cidade. Isto permite que práticas aconteçam. Estas práticas e usos do espaço favorecem a visibilidade dos jovens e autorizam seu engajamento. Deste modo, sentem-se aceitos, protegidos e "salvos" das "tentações" que, segundo eles, estão por toda parte. Tanto nas comunidades do rap, quanto nas comunidades da renovação, o traje é um diferencial e os coloca numa posição privilegiada. Alguns jovens, em particular os evangélicos, percebem nas roupas uma mudança de status. Falam do modo como são vistos, do que os vizinhos e amigos de tempos atrás dizem sobre eles hoje e do quanto ganharam respeito a partir do momento em que passaram a vestir roupas melhores (mais caras e de marcas famosas). Estes signos são formas de proteção, seja das "tentações", seja das vicissitudes. Poderiam ser interpretados como formas de alienação, na medida em que o consumo destes instrumentos alimenta as grandes indústrias. Entretanto, o que interessa neste estudo são as chamadas táticas de resistência: os usos e modos de "fabricação" artesanais, como diria De Certeau (2003), que vão ocorrendo lado a lado com as formas estabelecidas de produção. É um fazer atrelado a um lugar e a uma cidade onde o modo de "ajeitar" a vida, de criar condições para uma existência possível, se configura como um ethos local.

Percebo que existem saberes e fazeres próprios que são pouco ouvidos, quando o são. Em parte, porque os espaços existentes para a escuta estão fechados. 
Para Gadamer, a abertura para o outro "implica o reconhecimento de que devo estar disposto a deixar valer em mim algo contra mim..." (1997: 532). Assim, este estudo é uma tentativa de abertura dos espaços "existentes" ou institucionais para o que está aparentemente velado - o ponto de vista das pessoas sobre suas preocupações, interesses, desejos e maneiras de fazer.

\section{CONSIDERAÇÕES FINAIS}

Em Cosme de Farias há, comprovadamente, uma ausência de Estado. Isso aparece nos dados estatísticos, na escassez de entidades governamentais, tais como escolas, unidades básicas de saúde e equipamentos sociais e de cultura, e na falta de espaços formalizados que contribuam para o desenvolvimento pessoal e social das pessoas. Nesse caso, o bairro pode ser considerado pobre pela precarização no que concerne às políticas públicas, dando espaço para todas as formas de clientelismos.

É nesse contexto que identifico práticas como táticas de resistência, porque os jovens se apropriam dessas situações de adversidade que experimentam e inventam novas possibilidades e condições de existência a partir disto, vigiando para "captar no voo" possibilidades de ganho. Os jovens têm constantemente que "jogar com os acontecimentos para transformar as situações difíceis em ocasiões" (De Certeau 2003: 4).

Ser jovem pode causar desconforto aos adultos, neste caso àqueles com quem os jovens dividem espaço e poder no bairro e na cidade, e isso, aparentemente, gera descrédito em relação à sua "capacidade" de dar conta dos compromissos de uma comunidade. Entretanto, percebo que eles interferem numa dinâmica preestabelecida e colocam em discussão o modo como as coisas acontecem no bairro, compreendem as dificuldades, buscam outros espaços de interlocução dentro e fora do bairro e assumem um outro lugar. Deste modo, em um primeiro momento, as práticas de articulação política que desenvolvem dentro e fora do bairro são cruciais para o reconhecimento social dos jovens nesta perspectiva. Eles precisam legitimar-se como agentes dignos de credibilidade frente aos adultos, não apenas por serem jovens, mas, principalmente, para dividirem poder com os adultos e também com outros jovens no bairro. Em um segundo momento, as práticas operam como táticas de resistência, na medida em que os jovens usam as competências que detêm - trabalhos manuais e forçados, muitas vezes, sem qualquer valor econômico ou simbólico -, para investirem em algo que dê sentido à vida. Assim, carregar tijolos ou fazer biscates passam a ser alternativas que subsidiarão as bandas de rap, entre outras práticas que transformam a vida dos jovens no bairro. Por último, as práticas operam como táticas de resistência na medida em que os jovens fazem uso das comunidades e dos recursos provenientes delas para se protegerem das "tentações" experimentadas no bairro. Ou seja, fazer parte de bandas de rap ou 
das comunidades religiosas, por exemplo, configuram-se como possibilidades de proteção frente às vicissitudes experimentadas no bairro quando signos e significados atribuídos a essas comunidades facilitam o trânsito, sociabilizam os jovens e permitem que experiências desagradáveis vivenciadas no passado possam ser ressignificadas.

Essas práticas são, portanto, modos de fazer, são ocupações. É o encontro do ser com o uso que ele faz daquilo que está à mão, dos instrumentos de que dispõe. Elas se apropriam dos instrumentos que estão dados no mundo, podendo atuar como formas de enfrentamento ou de resistência às vicissitudes vivenciadas pelos jovens. Esta noção de prática se define pela experiência de significado. À medida que os jovens experimentam os acontecimentos e deles fazem uso nas atividades que realizam, tomam consciência desses acontecimentos, apropriam-se dos instrumentos que estão disponíveis e dão significados às suas experiências, transformando suas formas de existência, bem como seus mundos.

\section{BIBLIOGRAFIA}

ABU-LUGHOD, Lila, 1990, "The romance of resistance: tracing transformations of power through Bedouin women", American Ethnologist, 17 (1): 41-57.

ADORNO, Rubem de Camargo Ferreira, 1999, "A cidade como construção moderna: um ensaio a respeito de sua relação com a saúde e as 'qualidades de vida'”, Saúde e Sociedade, 8 (1): 17-30.

AUGÉ, Marc, 2004, Não-Lugares: Introdução a Uma Antropologia da Supermodernidade. Campinas, Papirus, 4. ${ }^{\mathrm{a}}$ ed.

AYRES, José Ricardo Mesquita, 2001, “Sujeito, intersubjetividade e práticas de saúde”, Ciência \& Saúde Coletiva, 6 (1): 63-72.

BAHIA, 2005, Dados Sociodemográficos do Bairro de Cosme de Farias. Salvador, SIG, Companhia de Desenvolvimento Urbano da Bahia - Conder.

BUCHOLTZ, Mary, 2002, "Youth and cultural practice", Annual Review of Anthropology, 31: 525-552.

BUCHOlTZ, Mary, A. C. LIANG, e Laurel A. SUTTON, 1999, Reinventing Identities: The Gendered Self in Discourse. Nova Iorque, Oxford University Press.

CAMPOS, Ricardo, 2009, "Entre as luzes e as sombras da cidade: visibilidade e invisibilidade no graffiti”, Etnográfica, 13 (1): 145-170.

CONCEIÇÃO, Antonio Carlos Lima da, 2009, “Teorias feministas: da 'questão da mulher' ao enfoque de gênero”, Revista Brasileira de Sociologia da Emoção, 8 (24): 738-757.

CONVERY, A. 2007, "Resisting 'Resistance': against a hegemonic trend in feminist theory”, comunicação arbitrada e apresentada ao congresso da Australasian Political Studies Association, Monash University, setembro. 
COSTA, Sandra Regina Soares da, 2010, “O que é ser 'novo' na Baixada Fluminense: notas sobre representações da juventude entre as camadas populares”, em Gilberto Velho e Luiz Fernando Dias Duarte (orgs.), Juventude Contemporânea: Culturas, Gostos e Carreiras. Rio de Janeiro, 7 Letras, 44-60.

De Certeau, Michel, 2003, A Invenção do Cotidiano 1: Artes de Fazer. Petrópolis, Vozes.

FERreIRA, Aurélio Buarque de Holanda, 1988, Dicionário Aurélio Escolar da Língua Portuguesa. Rio de Janeiro, Nova Fronteira.

FOUCAULT, M., s.d. [1984], "Michel Foucault: uma entrevista: sexo, poder e a política da identidade", entrevista com B. Gallagher e A. Wilson publicada originalmente em The Advocate, 400, 7 de agosto de 1984, pp. 26-30, 58. Disponível em <http://vsites.unb. $\mathrm{br} / \mathrm{fe} / \mathrm{tef} /$ filoesco/foucault/sexo.pdf $>$, trad. Wanderson Flor do Nascimento.

FRADIQUE, Teresa, 1999, "Nas margens... do rio: retóricas e performances do rap em Portugal", em Gilberto Velho (org.), Antropologia Urbana Cultura e Sociedade no Brasil e em Portugal. Rio de Janeiro, Zahar, 121-140.

GADAMER, Hans Georg, 1997, Verdade e Método. Petrópolis, RJ, Vozes.

MAGNANI, José Guillherme Cantor, 2000, “Quando o campo é a cidade”, em José Guillherme Cantor Magnani e Lilian de Lucca Torres (orgs.), Na Metrópole: Textos de Antropologia Urbana. São Paulo, Edusp/Fapesp, 2. ${ }^{\text {a }}$ ed., 12-53.

— - 2005, "Os circuitos dos jovens urbanos", Tempo Social: Revista de Sociologia da USP, 17 (2): 173-205.

—, 2006, Transformações na Cultura Urbana das Grandes Metrópoles. Disponível em $<$ http//www.n.a.u.org/magnanitransformacoes-a.html> (acesso em outubro de 2006).

MAGNANI, José Guilherme Cantor, e Bruna Mantese SOUZA (orgs.), 2007, Jovens na Metrópole: Etnografias de Circuitos de Lazer, Encontro e Sociabilidade. São Paulo, Terceiro Nome.

MENDES, José Manuel Oliveira, 2002, "O desafio das identidades”, em Boaventura de Sousa Santos (org.), A Globalização e as Ciências Sociais. São Paulo, Cortez, 503-540.

NOVAES, Regina, 2005, "Juventude, percepções e comportamentos: a religião faz diferença?”, em Helena Wendel Abramo e Pedro Paulo Martoni Branco (orgs.), Retratos da Juventude Brasileira: Análises de Uma Pesquisa Nacional. São Paulo, Fundação Perseu Abramo e Instituto Cidadania, 263-290.

PAIS, José Machado, 1993, Culturas Juvenis. Lisboa, Imprensa Nacional Casa da Moeda.

PAIS, José Machado, e Leila Maria BLASS (orgs.), 2004, Tribos Urbanas: Produção Artística e Identidades. Lisboa, Imprensa de Ciências Sociais.

PIMENTEL, Adriana Miranda, 2001, Um Olhar sobre os Olhares: Uma Etnografia do Centro de Referência do Adolescente em Salvador, Bahia. Salvador, Instituto de Saúde Coletiva da Universidade Federal da Bahia, dissertação de mestrado.

—, 2009, Práticas Culturais dos Jovens: Um Novo Olhar sobre os Jovens no Campo da Saúde. Salvador, Instituto de Saúde Coletiva da Universidade Federal da Bahia, dissertação de doutorado.

RICOUER, Paul, 1994, “Tempo e narrativa: a tríplice mimese”, em Paul Ricoeur, Tempo e Narrativa, vol. I. Campinas, Papirus, 85-131.

— 1 1996, Si Mismo como Otro. Madrid, Siglo XXI.

—_, 2000, "Narratividad, fenomenología y hermenéutica”, Anàlisi, 25: 189-207.

SANTOS, Jocélio Teles dos, s.d., Os Candomblés da Bahia no Século XXI. Disponível online em <http: //www.ceao.ufba.br> (acesso em setembro de 2008). 
SENNETT, Richard, 2003, Carne e Pedra: O Corpo e a Cidade na Civilização Ocidental. Rio de Janeiro/São Paulo, Record, 3. ${ }^{\mathrm{a}}$ ed.

VELHO, Gilberto, 1994, Projeto e Metamorfose: Antropologia das Sociedades Complexas. Rio de Janeiro, Zahar.

— (org.), 1999, Antropologia Urbana: Cultura e Sociedade no Brasil e em Portugal. Rio de Janeiro, Zahar.

—, 2006, "Juventudes, projetos e trajetórias na sociedade contemporânea", em Maria Isabel Mendes de Almeida e Fernanda Eugenio (orgs.), Culturas Jovens: Novos Mapas do Afeto. Rio de Janeiro, Zahar, 192-200.

VELHO, Gilberto, e Karina KUSCHNIR (orgs.), 2003, Pesquisas Urbanas: Desafios do Trabalho Antropológico. Rio de Janeiro, Zahar.

WEITZ, Rose, 2001, "Women and their hair: seeking power through resistence and accomodation", Gender and Society, 15 (5): 667-686.

WENGER, Etienne, 2001, Comunidades de Práctica: Aprendizaje, Significado e Identidad. Barcelona, Buenos Aires e México, Paidós. 